\title{
Effect of Insecurity on Economic Growth in Nigeria
}

\author{
Louis Sevitenyi Nkwatoh $^{1} \&$ Hiikyaa A. Nathaniel ${ }^{2}$ \\ ${ }^{1}$ Department of Economics, Yobe State University, Nigeria \\ ${ }^{2}$ Department of Agricultural Sciences, Federal College of Education, Nigeria \\ Correspondence: Louis Sevitenyi Nkwatoh, Department of Economics, Yobe State University, Damturu 234/ 620, \\ Nigeria. Tel: 234-8062-218-765. E-mail: sevinkwatoh@gmail.com
}

Received: May 29, 2018; Accepted: June 26, 2018; Published: September 27, 2018

\begin{abstract}
Many studies in conformity with theoretical underpinnings have shown that insecurity exerts a negative effect on economic growth. This study investigated the effect of insecurity on economic growth in Nigeria. The vector autoregressive model was employed using quarterly data from 2009Q1 to 2016Q4. The major findings show that economic growth and investment activities tend to increase during periods of insecurity. Also the rate of unemployment reduced during periods of insecurity. This implies that insecurity only threatens economic activities with no negative effect on the entire economy as conjectured by various economic theories. Thus, to continuously sustain the Nigeria's economic growth rate, the government needs to protect domestic and foreign investments by stepping up its national security.
\end{abstract}

Keywords: insecurity, terrorism, economic growth, VAR model, Nigeria

\section{Introduction}

One of the key determinants of economic development of any nation is peace and security. This inextricable link is predicated on the rule of law and socio-economic justice that protects domestic and foreign direct investments. Even though, the rule of law matters in the development process of any nation, deterring a frustrated group from engaging in illegal activities is also imperative. This can be achieved through equitable distribution of resources, reduction in poverty and income gaps and increase in employment opportunities.

The most appalling aspect of insecurity which persistently threatens global peace and tends to constrain the economic development of many economies nowadays is terrorism. The occurrences and persistence of insecurity (terrorism) with its debilitating effect is rooted in various economic theories. For instance, the "Relative Deprivation Theory" introduced by (Gurr, 1970) which suggests that insecurity emanates from a collective discontent caused by a sense of economic and social deprivations. Also, the "Religious Fanaticism Theory" which posits that a group of religious fanatics want to enforce a particular development policy with pre-determined set of ideological dictates (Özdamar, 2008).

In Nigeria, the spate of terrorist activities that breeds insecurity has threatened the economic progress of the nation over the years, specifically when the Boko Haram sect was declared a terrorist group. This has led to significant lost of human capital, closure of businesses and increased level of poverty mostly in the affected areas of the country. The root causes of insecurity (terrorism) in Nigeria conform to the theories enunciated above.

Studies in conformity with theoretical underpinnings have shown that insecurity exerts a negative effect on economic growth (see Blomberg, Hess \& Weerapana, 2004; Sandler \& Enders, 2005; Gaibulloev \& Sandler, 2009; Shabir, Naeem \& Ihtsham 2015; Fatima, Latif, Chugtai, Nazik \& Aslam, 2014; Dauda, 2014; Awojobi, 2014). The Nigerian case seems to be different because, the Boko Haram terrorist group that breeds insecurity is concentrated only in some Northern States where agriculture is still the mainstay of people and less prone to insecurity. Thus economic activities go unperturbed in the remaining part of the country implying that insecurity (terrorism) might only threaten the economic progress of Nigeria, rather than exert a negative effect on the entire economy as conjectured in economic theories. This study therefore analyses the controversy of whether insecurity exerts a negative effect on the economic growth of Nigeria or not.

The balance of the paper is as follows. Section 2 presents the review of literature. Section 3 contains the methodology while Section 4 presents the results and Section 5 contains the conclusion. 


\section{Theoretical Review}

Insecurity and terrorism are often used interchangeably and conceptualizing these two phenomena from a theoretical background basically requires an understanding from a wide range of scholarly ideological frameworks. Even though a plethora of studies have analyzed insecurity (terrorism) using different theoretical approaches, only three of such theories have an economic bearing - the 'Rational Choice Approach, Deprivation Theory and the Religious Fanaticism Theory'.

The rational choice theory is a framework for understanding and modelling social and economic behaviour (Blume $\&$ Easley, 2008). The main thrust of the rational choice theory is that individuals' rational decisions are premised on the expected benefits and costs of each action, and they seek to maximise the best course of action that will benefit their interest (Gupta, 2008). In relation to terrorism, the theory states that terrorist actions are driven from a conscious, rational and calculated decision to embark on an optimum and strategic course of action with the view of achieving socio-political goals (Sandler, Tschirhart \& Cauley 1983; Crenshaw, 1992; Wilson, 2000). Thus, terrorists must allocate their available resources (money, ammunitions and human resources) over time and space so as to maximize terrorism's net returns (Shughart, 2009). The rational choice theory suggests that terrorist' activities undermine policy effectiveness and constrain the development process of any nation. In Nigeria, terrorist activities often distort fiscal policy actions which unexpectedly increase government spending via extra budgetary spending. A major setback of the rational choice theory is its inability to provide appropriate parameters for measuring how a perceived action could serve as benefit or cost to the terrorists (see Wieviorka, 1993).

The Relative deprivation theory of terrorism introduced by (Gurr, 1970) suggests that political violence and terrorism occur mainly because of a collective discontent caused by a sense of relative deprivation. This theory is premised on the Frustration-Aggression hypothesis which assumes that frustration breeds aggressive behaviour. In economic sense, the theory attempts to explain the correlation between poverty and insecurity, implying the emergence of conflicts most especially in developing countries is caused by the prevalence of poverty. Empirical evidences from the works of Collier \& Hoeffler (2002); Bellow \& Miguel (2006); Ford (2007) indicate that poverty is the major cause of conflict in Africa. Awojobi (2014) observed that frustration, lack of income, unemployment prompted the Northern youths in Nigeria to become foot soldiers of the Boko Haram movement. Hess, and Weerapana (2004) provide empirical evidence showing that economic contraction in high-income countries has a significant effect on transnational terrorism.

The role of religion in shaping the lives of individuals and sanitizing the society cannot be overemphasized. This forms the basis of the Religious Fanaticism and Development theory. The negative effects of religion (fanaticism) on economic development and most especially lost of human capital has compelled most scholars around the world to provide arguments and counter arguments on the relevance of religion in the society. The theory posits that terrorism emanating from religious fanaticism always want to change or implement a particular development policy with pre-determined set of ideological dictates (Özdamar, 2008).

The nexus between religion and economic growth begins with Adam Smith's (1776) 'Inquiry into the Nature and Causes of the Wealth of Nations', who relates the laissez-faire philosophy to several aspects of religion. According to Smith, religious beliefs and activities are rational choices which make people respond to religious costs and benefits in a predictable and observable manner. Building on Smith's assertion, Wesley (1703-1791) hypothesizes that there is a two-way causation between religion and economic growth, but emphasizes more on hard work, selfreliance, and mutual aid.

The extreme role of religious fanaticism is the supply of human capital to terrorists' movements. Because terrorists groups are made of well educated men and women, they benefit from their potentials to the detriment of economic development of any nation. According to Krueger (2007) suicide bombers are well-educated and not from the poorer levels of society as conjectured in the relative deprivation theory. Thus, high levels of educational attainment are a signal of terrorist's commitment to the cause of violence. Gananath (1971) established that 80 per cent of insurgents in Sri Lanka had a reasonable level of education, and had both the motivation and the capacity to participate in what they viewed as a rational choice. They saw the uprising as the only solution to the economic and political difficulties facing Sri Lanka. Also, Maclearry (2008) observed that unemployment rose dramatically in the West Bank and Gaza Strip for college graduates relative to high school graduates in the 1980s

Summarily, economic growth can be influenced by terrorism and vice versa. The rational choice theory reveals that terrorism undermines policy effectiveness and constrains the development process of any nation. The negative effect of religious fanaticism on economic development is premised on the loss of human capital as enshrined in the Religious Fanaticism theory. In economic sense, the relative deprivation theory attempts to explain the correlation between insecurity and development via investment activities. 


\subsection{Empirical Literature Review}

A plethora of studies has shown that insecurity resulting from terrorists' activities negatively affects the economic growth of many countries. For instance, Blomberg, Hess and Weerapana (2004) showed that terrorists' activities rate is quite higher in the high income countries during periods of recession. Using panel regression analysis, these authors found that terrorism had a negative impact on economic growth. They concluded that the impact is less significant in advanced economies than developing countries. Similar results were obtained by Sandler and Enders (2004) when they compared the impact of terrorism on developed and developing countries reason being that developed countries had vast economies and any terrorist activity may result in reallocating resources among various sectors of the economy, which is not the case with the developing countries.

Gaibulloev and Sandler (2009) analyzed the impact of terrorism on per capita growth in Asia for the period 19702004. Their study found that terrorism hindered economic growth significantly. The impact seems to be stronger in developing countries when compared to developed ones because of the developed countries' resilience to terrorism due to their robust economies. Internal conflicts were found to be twice more effective in reducing growth than international conflicts.

Shabir, Naeem and Ihtsham (2015) used the Solow growth model to investigate the impact of terrorism on Pakistan's economic growth. They used secondary data from 1981 to 2012 and employed the co-integration technique. Their result suggested that terrorism had negatively affected the economic growth in Pakistan. Similarly, Fatima, Latif, Chugtai, Nazik and Aslam (2014) investigated the impact of terrorism activities on the economic growth of Pakistan and India using multiple regression analysis. They concluded that India's economic growth was not affected by terrorists' activities contrary to the case of Pakistan.

Choi (2015) evaluated the controversial issue of whether economic growth exerts a dampening effect on terrorism. A cross-national, time-series data analysis of 127 countries for the period 1970-2007 shows that countries with high levels of industrial growth rate are less disposed to domestic and international terrorist events, but are more likely to experience suicide attacks. Tahar, Arafet, Hadhek (2018) studied the effect of terrorism on economic growth and the transmission mechanism of its effect. They applied simultaneous equation models to panel data for a sample of eleven countries (six developing and five developed) over the period 2008-2015. Their findings revealed a positive effect of terrorism on economic growth for both developed and developing countries for the whole sample and a negative effect of economic growth on terrorism for the case of the total sample and the case of developing countries. Furthermore, the effect of unemployment on terrorism for all the country samples is negative. Gupta, Clements, Bhattacharya, and Chakravarti (2004) submitted that, armed conflict and terrorism lead to a higher share of defence spending in total government expenditure, which has a negative effect on the growth of low-and middle-income countries.

A handful of studies have analyzed the effect of insecurity on economic activities in Nigeria, particularly on the targeted areas of terrorists' activities. For instance, Dauda (2014) assessed the effect of Boko Haram crisis on economic activities in Yobe state. He employed descriptive statistics on monthly data from 2009 to 2014. He discovered that insecurity negatively affected the socio-economic activities within the state. In a related study, Awojobi (2014) examined the implications of the operations of the Boko Haram insurgency in the North East of Nigeria using descriptive statistics on secondary data from 2003 to 2009. His findings indicated that the atrocities of Boko Haram had severe implications on the economy and social lives of the people in that State. In another related study, Okarah (2014) centred his study on the causes and effect of insecurity in Nigeria. He employed a chronological historical antecedent of insecurity in Nigeria and also delved into the purview of the history, structure, mission and vision of the Nigerian police force. He identified inequality and poverty as root causes of insecurity in Nigeria which is difficult for the Nigerian police force to curtail.

Few studies have examined the nexus between insecurity and economic growth in Nigeria. For instance, Angahar and Iorpev (2012) found a negative relationship between capital market performance, economic growth and insecurity using multiple regression analysis. Using historically analysis from a sociological view point, Omadjohwoefe (2013) concluded that the atmosphere of insecurity impedes the attainment of sustainable development in Nigeria. A similar study by Olusegun (2016) shows that security and other related variables do not only contribute positively to economic growth in Nigeria. In the same vein, Ifeoma, Ndubuisi- Okolo and Anagbogu (2015) reached the same conclusion emphasizing that security challenges retards the socio-economic development of a country. Shuaibu and Lawong (2016) using a dynamic modelling approach concluded that the impact of insecurity is relatively higher on the external sector and fiscal variables compared with domestic policy variables. 
Contrarily, Ikpe and Nteegah (2014) employed a macro-econometric modelling of social insecurity, foreign direct investment and economic growth association in Nigeria and discovered that social insecurity stimulates the inflow of foreign technology, rather than inhibits it. Likewise Njoku and Nwachukwu (2015) using the Analysis of Variance (ANOVA) method found out that the Boko Haram terrorist group only poses threat to Nigeria's economy which can be tackled by the military.

\section{Methodology}

We employed the Vector Autoregressive (VAR) model to investigate the effect of insecurity on economic growth in Nigeria. Kendall (2001) defines the VAR model as an empirical investigation that facilitates statistical analysis of relationships among variables and is not constrained by any theoretical economic relationship. According to Stock and Mark (2001), the standard practice is to report the impulse response functions and the variance decompositions because they give more understanding to the relationships than the VAR regression. The VAR model assumes that the variables are stationary at different levels and not cointegrated.

\section{Model Specification:}

The VAR model of order $p$ is:

$$
Y_{t}=A(L) Y_{t-1}+U_{t}
$$

Where $Y_{t}$ is an ( $\left.\mathrm{n} \times 1\right)$ vector of endogenous variables, $Y_{t-1}$ is the corresponding lag term for each of the variables which is an (nxn) matrix of autoregressive coefficient vector of $\mathrm{i}=1,2 \ldots . \mathrm{k} . . U_{t}$ is an (nx1) vector of structural shocks with the variance-covariance matrix: $\mathrm{E}\left(U_{t} U_{t}\right)=\rho \sigma^{2}$.

The estimated VAR model that consists of a vector of endogenous variables:

$$
\left[\begin{array}{c}
G D P G R_{t} \\
G R G F C F_{t} \\
U M E_{t} \\
G T I_{t} \\
G R M E_{t}
\end{array}\right]=A_{1}\left[\begin{array}{c}
G D P G R_{t-1} \\
G R G F C F_{t-1} \\
U M E_{t-1} \\
G T I_{t-1} \\
G R M E_{t-1}
\end{array}\right]+\ldots+A_{p}\left[\begin{array}{c}
G D P G R_{t-p} \\
G R G F C F_{t-p} \\
U M E_{t-p} \\
G T I_{t-p} \\
G R M E_{t-p}
\end{array}\right]+U_{t}
$$

Where GDPGR is growth rate in gross domestic product; GRGFCF is growth rate in gross fix capital formation; UME is unemployment rate, GTI is global terrorism index and GRME is growth rate in military expenditure. The estimated lag length was determined using the Akaike Information Criterion (AIC), Schwarz Criterion (SC), Sequential modified LR test statistic, Final prediction error (FPR), Hannan-Quinn (HQ) information criterion

\section{Testing the Properties of Time Series Data}

It is important that the time series properties of a set of data are checked prior to any econometric analysis. In so doing, we tend to avoid any spurious results that may occur in case the series is non-stationary otherwise has unit root. A stationary time series is one whose statistical properties such as mean, variance, autocorrelation, etc. are all constant over time. A non-stationary series, $\mathrm{y}_{\mathrm{t}}$ is said to be integrated of order $d$ and is made stationary by differencing it $d$ times, i.e., a non-stationry series $\mathrm{y}_{\mathrm{t}} \rightarrow \mathrm{I}(\mathrm{d})$ to become stationary. If a series is stationary in level, then $d=0$ or $\mathrm{y} \rightarrow \mathrm{I}(0)$. If a series is differenced once to become stationary then $\mathrm{y}_{\mathrm{t}} \rightarrow \mathrm{I}(1)$.

All the series were tested for stationarity by using the Augmented Dickey Fuller (ADF) and Phillip-Perron tests. Following Greene's (2003) approach, the unit root test based on Augmented Dickey Fuller (ADF) follows equation:

$$
\begin{gathered}
Y_{t}=\alpha+\beta Y_{t-1}+\sum_{i=1}^{n} \beta_{j} \Delta Y_{t-1}+\varepsilon \ldots \\
Y_{t}=\alpha+\gamma t+\beta Y_{t-1}+\sum_{i=1}^{n} \beta_{j} \Delta Y_{t-1}+\varepsilon
\end{gathered}
$$

Equations (3.1) and (3.2), indicate ADF tests without trend and with trend respectively.

The unit root test based on Phillip-Perron follows equation:

$$
\Delta \mathrm{X}_{t}=a+b X_{t-1}+c\left(t+\frac{T}{2}\right)+\mu_{t}
$$


$a, b$, and $c$ are the coefficients and $T$ is the total number of observations. The $A D F$ and $P P$ unit root tests posit a null hypothesis $\beta=0$ versus an alternative hypothesis $\beta<0$, where the $A D F$ and $P P$ statistics is compared with the observed Mackinnon critical value 5\% level of significance. If ADF and PP statistics is greater than the Mackinon criterion, we reject the null hypothesis and conclude that the time series is stationary.

\section{Source of Data}

The study used quarterly data from 2008:Q1 to 2016:Q4 which takes into consideration the intense activities of terrorists' activities in the country. The variables in the VAR model are: GDPGR which captures the growth rate in gross domestic product; growth rate in gross fix capital formation (GFGFCF) measures the level of investment; unemployment rate (UME), insecurity measured by the rate of terrorists' activities within the country and proxied by the global terrorism index (GTI) and growth rate in military expenditure (GRME). The data sets are extracted from the International Financial,Statistics IFS CD-ROM published by the IMF and World Development Indicators CD-ROM published by the World Bank. Data on GTI is obtained from Institute for Economics and Peace website (https://tradingeconomics.com).

\section{Presentation and Analysis of Results}

\section{Unit Root Test}

The empirical analysis began with a prior investigation of stationary properties of the time series using both $A D F$ and $P P$ tests. Both tests reported on Table 1 indicate that all the variables are stationary at different levels. The global terrorism index (GTI) is stationary at levels; while GDP growth rate (GDPGR), growth rate in gross fix capital formation (GRGFCF), and unemployment (UME) are stationary after first difference i.e., integrated of order one. The growth rate in military expenditure (GRME) is stationary after second difference i.e., integrated of order two. The study therefore used a reduced form VAR since all the variables are stationary at different levels.

Table 1. Unit Root Test Results

\begin{tabular}{|c|c|c|c|c|c|c|c|}
\hline \multirow[t]{3}{*}{ Variable } & \multicolumn{3}{|c|}{$\begin{array}{l}\text { Augmented Dickey Fuller } \\
\text { With Intercept and Trend }\end{array}$} & \multicolumn{3}{|c|}{$\begin{array}{l}\text { Phillip Perron } \\
\text { with Intercept and Trend }\end{array}$} & \multirow[t]{3}{*}{$\begin{array}{l}\text { Order of } \\
\text { Integration }\end{array}$} \\
\hline & Levels & $1^{\text {st }}$ Difference & $2^{\text {nd }}$ & Levels & $1^{\text {st }}$ Difference & $2^{\text {nd }}$ & \\
\hline & & & Difference & & & Difference & \\
\hline GDPGR & -1.27087 & -3.75432 & & -0.85884 & -3.81423 & & $\mathbf{I}(\mathbf{1})$ \\
\hline GRGFCF & -2.48770 & -3.73486 & & -1.99755 & -4.24167 & & (1) \\
\hline UME & -2.16835 & -3.697135 & & -1.58855 & -3.92141 & & $\mathbf{I}(\mathbf{1})$ \\
\hline GTI & -3.79938 & & & -4.97812 & & & $\mathbf{I}(\mathbf{0})$ \\
\hline GRME & -2.05896 & -2.63132 & -4.21407 & -1.391162 & -3.320392 & -6.833473 & $\mathbf{I}(2)$ \\
\hline
\end{tabular}

Note: The ADF and PPT critical value at 5\% level is -3.5731 . The critical value is based on the Mckinnon criterion. The optimal lag is selected on the basis of the Akaike Information Criterion (AIC). I(*) shows the level of integration

\section{Lag Selection Criteria and Serial Correlation Test}

Table 2 shows the optimal lag-length of the estimated VAR model. To ensure that the estimates from the reduced form VAR are consistent, an appropriate lag order of 2 is used in the estimation based on the selection test criteria reported on Table 2 .

Table 2. VAR Lag Order Selection Criteria

\begin{tabular}{lllllll}
\hline Lag & LogL & LR & FPE & AIC & SC & HQ \\
\hline 0 & -83.20288 & NA & 0.000375 & 6.300205 & 6.538099 & 6.372932 \\
1 & 22.47963 & 166.0725 & $1.22 \mathrm{E}-06$ & 0.537169 & 1.964531 & 0.973528 \\
$\mathbf{2}$ & $\mathbf{9 1 . 3 1 1 9 9}$ & $\mathbf{8 3 . 5 8 2 1 5}$ & $\mathbf{6 . 4 3 E - 0 8 *}$ & $\mathbf{- 2 . 5 9 3 7 1 4} *$ & $\mathbf{0 . 0 2 3 1 1 7}^{*}$ & $\mathbf{- 1 . 7 9 3 7 2 2}^{*}$ \\
\hline
\end{tabular}

* indicates lag order selected by the criterion. LR: sequential modified LR test statistic, FPE: Final prediction error, AIC: Akaike information criterion, SC: Schwarz information criterion

HQ: Hannan-Quinn information criterion (each test at 5\% level) 
The, the appropriate lag length of the estimated VAR model is selected based on the absence of serial correlation. Table 3 shows the serial correlation LM test which indicates that the estimated VAR model at lag 2 is free from serial correlation because the p-value is greater than 0.05 .

Table 3. VAR Serial Correlation LM Test .

\begin{tabular}{cll}
\hline Lags & LM-Stat & Prob \\
\hline 1 & 28.22461 & 0.2976 \\
2 & 16.71548 & 0.8919 \\
3 & 7.361583 & 0.9998 \\
4 & 149.1800 & 0.0000 \\
5 & 32.99013 & 0.1313 \\
\hline
\end{tabular}

\section{Stability Test}

The next important test that follows the serial correlation LM-test is the VAR stability test. Fig 1 shows that all the roots lie inside the circle implying the estimated VAR is stable. Hence all initial preliminary VAR diagnostics have been fulfilled which permits the study to proceed with further analyses.

\section{Inverse Roots of AR Characteristic Polynomial}

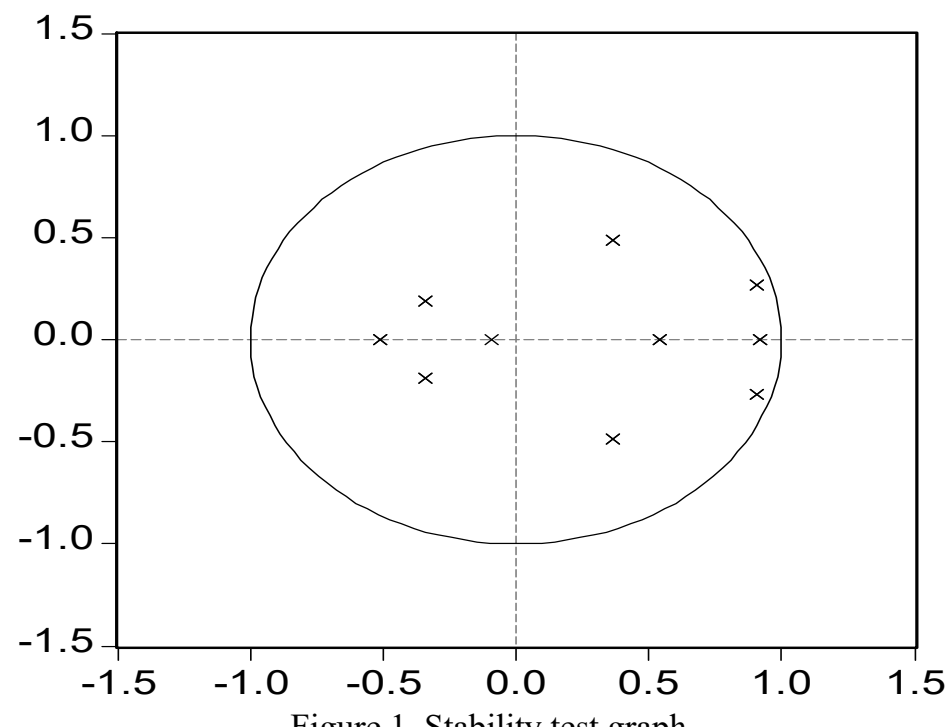

Figure 1. Stability test graph

\section{Impulse Response Graphs}

Fig 2 shows the impulse response graphs of the variables extracted from the estimated VAR model. The graphs show the responses of GDP growth rate (GDPGR), growth rate in gross fix capital formation (GRGFCF), and unemployment (UME) to innovations in growth rate in military expenditure (GRME), global index (GTI) as well as unemployment (UME) as indicated on the different panels below. Quarter one to four is considered as the short run, quarter 5 five to eight is the medium term, while quarter nine to twelve is the long run.

The graphs of panel A and D are similar showing that the responses of GDGR and GRGFCF to a one standard innovation in GRME are negative both in the short and medium term, while the effect becomes positive only in the long run. This implies that economic activities start booming only in the long run when national security must have been guaranteed in the short and medium terms as a result of the rising military expenditure.

The graph of panel B indicates that the response of GDPGR to a one standard innovation in GTI is positive both in the short and long runs, while the graph of panel E shows that the effect of GTI on GRGFCF is positive in the short and medium terms and fizzles out in the long run. This result contradicts the findings of (Bloomberg et al., 2004; Sandle \& Enders 2005) for developed and developing countries; (Gaibulloev \& Sandler, 2009; Shabir et al., 2015) for Pakistan suggesting that the dimension of influence of insecurity differs across a set of countries and greatly depends on the nature of terrorists' activities and the sectors under attack. For instance, Choi (2015) notes 
that only some forms of economic growth are associated with terrorist activity, while higher levels of industrial economic growth are associated with higher levels of suicide attacks. This result conforms to Choi's findings because the intensity of terrorists' activities is mostly concentrated in some parts of Northern Nigeria were agriculture is the mainstay and less prone to terrorism. Evidently, Nigeria has experienced positive growth rates during intense Boko Haram crises and even became the leading economy in Africa in 2015 buttressing the fact that this aspect of insecurity only threatens the Nigerian economy.

The graph of panel C indicates that GDPGR responds positively to a one standard innovation in UME both in the short and long runs. This particular finding is an economic puzzle most especially as it debunks the Okun's law which has empirically established that there is an inverse relationship between unemployment and economic growth. However, this scenario is evident in Nigeria because statistic shows that unemployment keeps increasing, while the economy continuously records positive growth rates. The effect of unemployment on GRGFC is insignificant during periods of insecurity in Nigeria. This is because a greater proportion of investment activities are concentrated in less prone terrorists' zones.

Panels $\mathrm{H}$ and I shows that during periods of insecurity, the response of GRME to a one standard innovation in GTI and UME is insignificant throughout the entire periods. This implies that other forms of insecurity such as kidnapping, militancy, violence, farmer-grazier problems, religious crisis etc, may also be responsible for the rising GRME. But on the other hand, a standard innovation in unemployment creates a positive effect on GRME reason being that the unemployed are mostly graduates from tertiary institutions who may likely invest their time and knowledge in illegal activities due to limited opportunities. The graph of panel J dies down gradually in the long run indicating that the growth in military expenditure curtails the activities of the unemployed in Nigeria. Lastly, a one standard innovation in GTI reduces the level of unemployment in Nigeria as depicted on panel K. Possibly this may be due to: one, employment strategies and policies over the years to deterred youths from illegal activities cum terrorism by the federal government which coincided with periods of intense terrorist activities in Nigeria. The second plausible dimension to this is that the terrorist group over the years has recruited idle youths. This second argument validates the religious fanaticism theory which suggests that human capital for terrorists' movement is provided by educated men and women. Thus, unemployment rate is reduced via supply of human capital to terrorism and through government strategies.

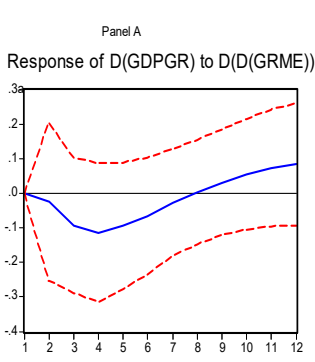

PanelE

Response of $D(G R G F C F)$ to $G T I$

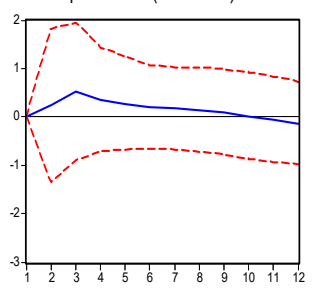

Panell

Response of $\mathrm{D}(\mathrm{D}(\mathrm{GRME}))$ to $\mathrm{D}(\mathrm{UME})$

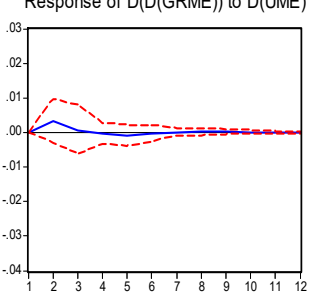

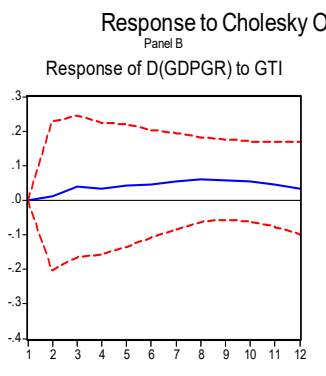

Panel $\mathrm{F}$
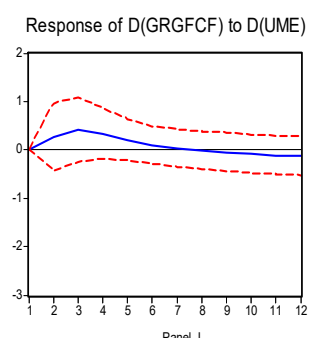

Panel $\int$

Response of $D(U M E)$ to $D(D(G R M E))$

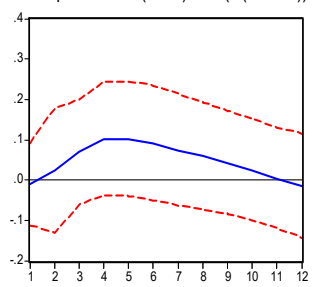

Panel D

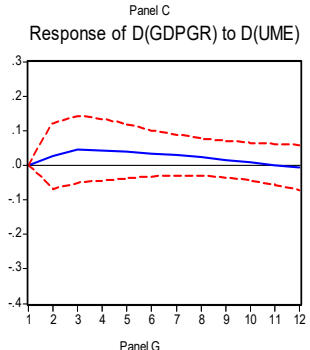

Panel $G$

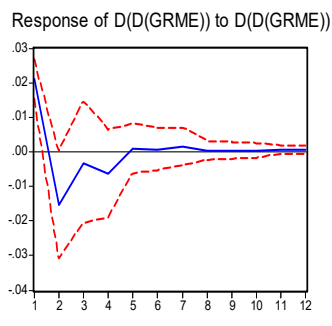

PanelK

Response of D(UME) to GTI

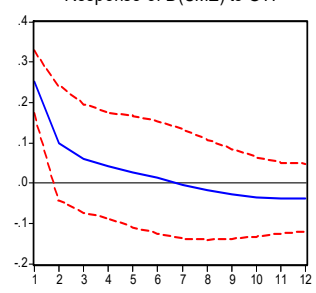

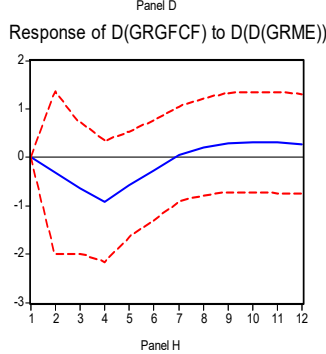

Response of $D(D(G R M E))$ to $G T$ I

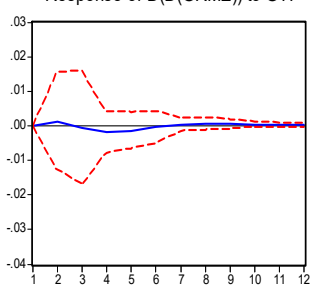

Panel L

Response of $D(U M E)$ to $D(U M E)$

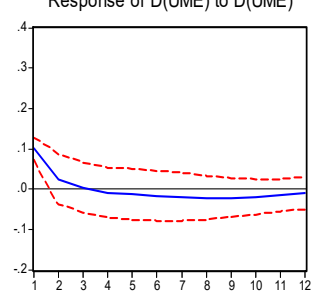

Figure 2. Impulse response graphs 


\section{Conclusion}

The study investigated the effect of insecurity on the economic growth of the Nigerian economy. We employed the vector autoregressive model on quarterly data from 2008Q1 to 2016Q4. The major findings show that economic growth and investment activities tend to increase during periods of insecurity (proxied by terrorism), while unemployment rate reduced within the entire period. The result also suggests that economic expansion starts only in the long run when the national security of the country must have been guaranteed in the short and medium terms as a result of rising military expenditure. The implication of the findings is that insecurity only threatens economic activities with no negative effect on the entire economy. To continuously sustain Nigeria's economic growth rate, the government needs to protect domestic investment and attract foreign direct investment by stepping up its national security. Secondly, the government needs to create more employment opportunities that will fully engage Nigerian youths. This will reduce idleness among youths and discourage their willingness to engage in terrorists activities.

\section{References}

Adam, S. (1937). An Inquiry into the Nature and Causes of the Wealth of Nations, Sixth Edition.

Angahar, P., \& Iorpev, L. (2012). An Analysis of the Effects of Insecurity on Capital Market and Economic Growth of Nigeria. International Journal of Academic Research in Accounting, Finance and Management Sciences, 2(3), 207-216.

Oladayo, N. A. (2014). The Socio-Economic implications of Boko-Haram Insurgency in North-East Nigeria. InternationalJournal of Innovation and Scientific Research, 11(1), 144-150

Bellow, J., \& Miguel, E. (2006). War and Local Collective Action in Sierra Leone. Uunpublished working paper, University of California, Berkeley.

Blomberg, B, Hess, G., and Weerapana, A. (2004). Economic conditions and Terrorism. European Journal of Political Economy, 20, 463-478. https://doi.org/10.1016/j.ejpoleco.2004.02.002

Blume, E., \& Easley, D (2008). Rationality. The New Palgrave Dictionary of Economics, $2^{\text {nd }}$ Edition. https://doi.org/10.1057/978-1-349-95121-5_2138-1

Choi, S. (2015). Economic Growth and Terrorism: Domestic, International, and Suicide. Oxford Economic Papers, 157-181. https://doi.org/10.1093/oep/gpu036

Collier, P., \& Hoeffler, A. (2002). On the Incidence of Civil War in Africa. Journal of Conflict Resolution, 46(1), 13-28. https://doi.org/10.1177/0022002702046001002

Crenshaw, M. (2000). The psychology of terrorism: An agenda for the 21st century. Political Psychology, 21, 40520. https://doi.org/10.1111/0162-895X.00195

Dauda, M. (2014). The Effect Of Boko Haram Crisis On Socio-Economic Activities in Yobe State. The International Journal of Social Sciences and Humanities Invention, 1, 251-257

Fatima, M., Latif, M., Chugtai, M., Nazik., H., \& Aslam, S (2014).Terrorism and its Impact on Economic Growth: Evidence from Pakistan and India. Middle-East Journal of Scientific Research, 22(7), 1033-1043

Gaibulloev, K., \& Sandler, T. (2009). The Impact of Terrorism and Conflicts on Growth in Asia. Economics and Politics, 21(3), 359-383.

Gananath, O. (1974). Some Comments on the Social Backgrounds of the April 1971 Insurgency in Sri Lanka (Ceylon). Journal of Asian Studies 33(3).

Gupta, D. (2008). Understanding Terrorism and Political Violence, New York: Routledge.

Gupta, S., Clements, B., Bhattacharya, R., \& Chakravarti, S. (2004). Fiscal Consequences of Armed Conflict and Terrorism in Low- And Middle-Income Countries. European Journal of Political Economy, 20(2), 403-421

Gurr, T. (1970). Why Men Rebel, Princeton: Princeton University Press

Ifeoma, O., Ndubuisi- Okolo, P., \& Anagbogu, T. (2015). Security Challenges and The Implications For Business Activities In Nigeria: A Critical Review. Journal of Policy And Development Studies, 9(2).

Ikpe, M., and Nteegah, A. (2015). Macro-Econometric Modelling of Social Insecurity, Foreign Direct Investments and Economic Growth Association. Int. J. Soc. Sci. Manage, 1(4), 129-138.

Krueger, A. (2007). What Makes a Terrorist: Economics and the Roots of Terrorism. Princeton University Press.

McCleary, M. (2008). Salvation, Damnation, and Economic Incentives. Journal of Contemporary Religion 22(1). 
https://doi.org/10.1080/13537900601114503

Njoku, J., \& Nwachukwu, J. (2015). The Effects of Boko Haram's Insecurity on Nigeria's Economy. International Journal of Arts and Humanities, 4(15), 26-41.

Okarah, I. (2014). Causes And Effects of Insecurity in Nigeria: The Challenges and Relevance of the Nigerian Police Force as a Panacea. Unpublished M.sc Thesis, University of Nigeria.

Olusegun, A. (2016). Economic Growth Amidst Insecurity: The Nigeria Experience. Research Journal of Finance and Accounting, 7(7), 56-71

Omadjohwoefe, S. (2013). Insecurity and Sustainable Development: The Boko Haram Debacle in Nigeria. American International Journal of Social Science, 2(7), 82-88.

Özdamar, O. (2008). Theorizing Terrorist Behaviour: Major Approaches and their Characteristics. Defence against Terrorism Review, 1(2), 89-101.

Sandler, T., \& Lapan. H. (1988). The calculus of dissent: An analysis of terrorists' choice of targets. Synthése, 76, 245-61. https://doi.org/10.1007/BF00869591

Sandler, T., Tschirhart, J., \& Cauley, J. (1983). A theoretical analysis of Transnational Terrorism. American Political Science Review, 77, 36-54. https://doi.org/10.2307/1956010

Sandler, T., \& Enders, W. (2004). An economic perspective on transnational terrorism. European Journal of Political Economy 20(2), 301-316.

Shabir, H., Naeem, A., \& Ihtsham, P. (2015). Impact of Terrorism on Economic Development in Pakistan. Pakistan Business Review, 701-722

Shuaibu, M., \& Lawong, D. (2016). An Analysis of the Macroeconomic Impact of Insecurity on Nigeria: A Dynamic Modeling Approach. Journal of Social and Management Sciences, 2(1), 1-23.

Shughart, W. (2011). Terrorism in Rational Choice Perspective. In Christopher J. Coyne \& Rachel L. Mathers (Eds.), The Handbook on the Political Economy of War (pp. 126-153). Cheltenham, UK: Edward Elgar Publishing, Inc. https://doi.org/10.4337/9781849808323

Stock, J., \& Mark, W. (2001). Vector Autoregressions. Journal of Economic Perspectives, 15(4), 101-115. https://doi.org/10.1257/jep.15.4.101

Tahar, L., Arafet, H., \& Zouhaier, H. (2018). Terrorism and Economic Growth. International Journal of Economics and Financial Issues, 8(1), 175-178.

Wieviorka, M. (1993). The making of terrorism. Translated by D. G. White. Chicago: University of Chicago Press.

Wilson, M. (2000). Toward a model of terrorist behaviour in hostage-taking incidents. Journal of Conflict Resolution, 44, 403-24. https://doi.org/10.1177/0022002700044004001

\section{Copyrights}

Copyright for this article is retained by the author(s), with first publication rights granted to the journal.

This is an open-access article distributed under the terms and conditions of the Creative Commons Attribution license (http://creativecommons.org/licenses/by/4.0/). 